\title{
Correction to: elaborator: A Novel App for Insights into Laboratory Data of Clinical Trials
}

Silke Janitza, $\mathrm{PhD}^{1} \cdot$ Madhurima Majumder, $\mathrm{PhD}^{2} \cdot$ Franco Mendolia, $\mathrm{PhD}^{3} \cdot$ Steffen Jeske, $\mathrm{MSc}^{4}$. Hermann Kulmann, PhD ${ }^{1}$

Published online: 22 July 2021

(c) The Drug Information Association, Inc 2021

Correction to: Therapeutic Innovation \& Regulatory Science https://doi.org/10.1007/s43441-021-00318-4

Due to a Production error the original article was published without corrections. The corrected version of the article has now been published.

The original article can be found online at https://doi.org/10.1007/ s43441-021-00318-4.

Silke Janitza

silke.janitza@bayer.com

1 Research \& Development, Pharmaceuticals, Statistics and Data Insights, Bayer AG, 13342 Berlin, Germany

2 Bayer US LLC, Whippany, NJ, USA

3 Bayer AG, Wuppertal, Germany

4 Chrestos Concept GmbH \& Co. KG, Essen, Germany 